\title{
Disubstituted Aminoanthraquinone-based Multicolor Photoinitiators: Photoinitiation Mechanism and Ability of Cationic Polymerization under Blue, Green, Yellow and Red LEDs
}

\author{
J. Zhang ${ }^{\perp, \xi, \dagger}$, J. Lalevée ${ }^{\xi, \mu}$, N. S. Hill ${ }^{\perp, \#}$, K. Launay ${ }^{\dagger}$, F. Morlet-Savary, ${ }^{\xi, \mu}$, B. Graff ${ }^{\xi, \mu}$, M. H. Stenzel ${ }^{\dagger}$, \\ M. L. Coote ${ }^{\perp, \#^{*}}$, P. Xiao ${ }^{\perp, \xi, t^{*}}$ \\ ${ }^{\perp}$ Research School of Chemistry, Australian National University, Canberra, ACT 2601, Australia. \\ \#ARC Centre of Excellence for Electromaterials Science. \\ 乡Université de Haute-Alsace, CNRS, IS2M UMR 7361, F-68100 Mulhouse, France \\ ${ }^{\mu}$ Université de Strasbourg, France \\ ${ }^{\dagger}$ School of Chemistry, University of New South Wales, Sydney, NSW 2052, Australia.
}

Corresponding Authors: pu.xiao@anu.edu.au; michelle.coote@anu.edu.au

\begin{abstract}
:
The investigation and clarification of the photoinitiation mechanism of novel systems are of importance for the design and development of compounds with high photoinitiation efficiency of photopolymerization. Some disubstituted aminoanthraquinone derivatives have been reported to exhibit interesting photochemical/photophysical properties, and have the potential to act as high performance multicolor photoinitiators under the irradiation of various wavelength of visible light from light-emitting diodes (LEDs). Herein, three disubstituted aminoanthraquinone derivatives, i.e. 1-amino-4hydroxyanthraquinone, 1,4-diaminoanthraquinone, and 1,5-diaminoanthraquinone, with iodonium salt and $\mathrm{N}$-vinylcarbazole as additives, have been investigated. Their photoinitiation mechanism was studied using fluorescence spectroscopy, laser flash photolysis, steady state photolysis, computational quantum chemistry and electron spin resonance spin trapping techniques. Then, their photoinitiation ability for the cationic photopolymerization of epoxide and divinyl ether monomers under the irradiation of diverse
\end{abstract}


LEDs (i.e. blue, green, yellow, and red LEDs) was investigated. The types and positions of substituents were found to play a vital role in the photoreactivity and photoinitiation ability of the disubstituted aminoanthraquinone derivative-based photoinitiating systems.

Keywords: disubstituted aminoanthraquinone, photoinitiator, photoinitiating system, cationic photopolymerization, LED

\section{Introduction:}

Photopolymerization technology $y^{1-10}$ is a promising approach in various applications such as 3D printing, ${ }^{11-21}$ (bio)medicine, optics technologies, microelectronics, and materials science. ${ }^{16,}{ }^{22-32}$ In photopolymerizable formulations, the photoinitiator (PI) plays the significant role of absorbing the light and then triggering the transformation of liquid monomers and resins into solids for the fabrication of various materials. ${ }^{1,5,33,34}$ A challenge is to design and develop multicolor PIs of polymerization that can work under the whole visible light range (i.e. blue, green, yellow, and red light), as it can offer the more flexibility and easier accessibility to the photopolymerization processes under any irradiation conditions. Several examples have been reported to work under the panchromatic visible light irradiation (400 - 700 $\mathrm{nm})$, such as 2,7-di-tert-butyldimethyldihydropyrene $\mathrm{DHP},{ }^{35}$ the indanedione derivative $\mathrm{D} \_1{ }^{36}$ the polyfunctional thiophene derivative PQXTP, ${ }^{37}$ the thioxanthone derivative TX-NPG, ${ }^{38}$ and curcumin. $^{39}$ However, to the best of our knowledge, none of these reported multicolor PIs exhibits high photoinitiation ability upon exposure to all wavelengths of light, especially long-wavelength irradiation. It is thus desirable to explore and develop multicolor PIs with high efficiency under the irradiation of light delivered from all colours of light-emitting diodes (LEDs; e.g. blue LED, green LED, yellow LED, and red LED), ${ }^{40-43}$ as LEDs have been attracting increasing attention for photopolymerization ${ }^{44}$ due to advantages over other light sources such as better light output, higher operating efficiency, safer usage, and lower cost. 1 , 40, 45 
Recently, several 9,10-anthraquinone derivatives have emerged as efficient photoinitiators including 1,8-dihydroxyanthraquinone ${ }^{46}, 1,2,4$-trihydroxyanthraquinone ${ }^{47}$, and oil blue $\mathrm{N}^{48}$ as blue light-, green light-, and red light-sensitive PIs respectively. This suggests that the substituents of anthraquinone derivatives can be used to tune their performance as PIs, and that anthraquinone derivatives with suitable substituents may act as multicolor PIs. In this study several disubstituted aminoanthraquinone derivatives (DAAQs), i.e. 1-amino-4-hydroxyanthraquinone (AHAQ), 1,4-diaminoanthraquinone (14-DAAQ), and 1,5-diaminoanthraquinone (15-DAAQ), in combination with the additives (i.e. iodonium salt and $N$ vinylcarbazole), are investigated for their photoinitiation mechanism and ability to initiate cationic photopolymerization under blue, green, yellow, and red LED light.

\section{Experimental Section}

\section{Materials}

The investigated disubstituted aminoanthraquinone derivatives (DAAQs), i.e. 1-amino-4hydroxyanthraquinone (AHAQ), 1,4-diaminoanthraquinone (14-DAAQ), and 1,5-diaminoanthraquinone (15-DAAQ) were obtained from EGA-Chemie KG, Fluka AG and Sigma- Aldrich respectively. Their chemical structures are illustrated in Scheme 1. Diphenyliodonium hexafluorophosphate (Iod) and $N$ vinylcarbazole (NVK) were used as the additives of the disubstituted aminoanthraquinone-based photoinitiating systems, while (3,4-epoxycyclohexane)methyl 3,4-epoxycyclohexylcarboxylate (EPOX) and tri(ethylene glycol) divinyl ether (DVE-3) were used as benchmark monomers (Scheme 2) for cationic photopolymerization. The additives and monomers were all obtained from Sigma-Aldrich.
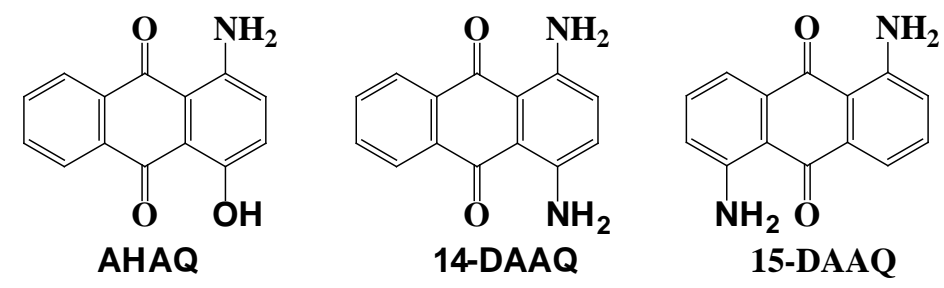

Scheme 1. Chemical structures of the studied disubstituted aminoanthraquinone derivatives (AHAQ, 14DAAQ, and 15-DAAQ). 


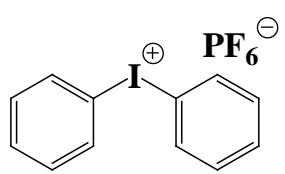

Iod

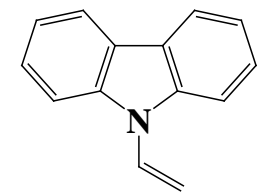

NVK

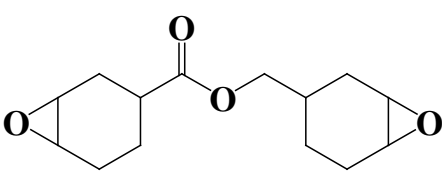

EPOX

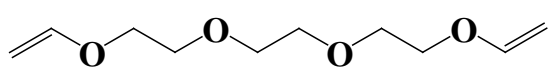

DVE-3

Scheme 2. Chemical structures of the investigated additives (Iod and NVK) of the disubstituted aminoanthraquinone-based photoinitiating systems and monomers (EPOX and DVE-3) for cationic photopolymerization.

\section{Computational Methodology}

All electronic structure calculations were performed using the Gaussian 16 software ${ }^{49}$. All closed shell calculations were performed with restricted density functional theory (DFT) calculations, and open-shell calculations were performed with unrestricted DFT, all using the M06- $2 \mathrm{X}^{50}$ functional with the def2TZVP $^{51}$ basis set. Excited states were calculated with time-dependent DFT (TD-DFT) at the M062X/def2-TZVP level of theory; in all cases implicit solvent effects were accounted for with the SMD ${ }^{52}$ model of acetonitrile.

\section{Irradiation Sources}

Four different household LED bulbs were used as irradiation devices for photopolymerization reactions: Blue LED (emission wavelength centered at $455 \mathrm{~nm}$; incident light intensity: $60 \mathrm{~mW} \mathrm{~cm}{ }^{-2}$ ), Green LED (518 nm; $60 \mathrm{~mW} \mathrm{~cm}{ }^{-2}$ ), Yellow LED (594 nm; $30 \mathrm{~mW} \mathrm{~cm}{ }^{-2}$ ), and Red LED (636 nm; 60 $\left.\mathrm{mW} \mathrm{cm}^{-2}\right)$.

\section{Fluorescence Experiments}

The fluorescence properties of DAAQs in acetonitrile were studied using the Varian Cary Eclipse Fluorescence Spectrophotometer. The fluorescence quenching of DAAQs by Iod were investigated from 
the classical Stern-Volmer treatment ${ }^{2}\left(I_{0} / I=1+k_{\mathrm{q}} \tau_{0}\left[\right.\right.$ Iod]; where $I_{0}$ and $I$ stand for the fluorescent intensity of DAAQs in the absence and the presence of Iod, respectively; $\tau_{0}$ stands for the lifetime of DAAQs in the absence of Iod).

\section{Laser Flash Photolysis}

Nanosecond laser flash photolysis (LFP) experiments were carried out using a Q-switched nanosecond Nd/YAG laser ( $\lambda_{\text {exc }}=355$ nm, 9 ns pulses; energy reduced down to $10 \mathrm{~mJ}$ ) from Continuum (Minilite) and an analyzing system consisted of a ceramic xenon lamp, a monochromator, a fast photomultiplier and a transient digitizer (Luzchem LFP 212). ${ }^{53}$

\section{Steady State Photolysis Experiments}

DAAQs in the presence of Iod in acetonitrile were irradiated with the green LED@518 nm (60 $\mathrm{mW} \mathrm{cm}^{-2}$ ), and the UV-vis spectra were recorded using the Lambda $950 \mathrm{UV} / \mathrm{VIS} / \mathrm{NIR}$ Spectrophotometer (PerkinElmer) at different irradiation time.

\section{Electron Spin Resonance Spin Trapping (ESR-ST) Experiments}

ESR-ST experiment was carried out using the Bruker EMX-plus X-Band ESR Spectrometer. The radicals were generated at room temperature upon the blue LED exposure under argon and trapped by phenyl-N-tert-butylnitrone (PBN) according to a procedure ${ }^{54}$ described elsewhere in detail. The ESR spectrum simulation was carried out with the WINSIM software.

\section{Cationic Photopolymerization of Multifunctional Monomers}

The cationic photopolymerization reactions of the multifunctional monomers (EPOX and DVE-3) in the presence of different DAAQ-based photoinitiating systems upon exposure to the various LED 
bulbs were monitored using ATR-IR (BRUKER, IFS 66/s). To this end, a layer of liquid formulation ( $20 \mu \mathrm{m}$ thick) was coated on the surface of the ATR horizontal crystal and the ATR-IR spectra of the sample was recorded at different time intervals during the LED irradiation. The evolution of the epoxy group content of EPOX and the double bond content of DVE-3 were followed by ATR-IR spectroscopy using the bands at approximately $790 \mathrm{~cm}^{-1}$ and $1615 \mathrm{~cm}^{-1}$, respectively. ${ }^{55}$ The cationic photopolymerization of EPOX was carried out exposed to the air, while the cationic photopolymerization of DVE-3 was conducted in laminate. The degree of epoxy group or double bond conversion $C$ at time $t$ during the photopolymerization is calculated from $C=\left(\mathrm{A}_{0}-\mathrm{A}_{\mathrm{t}}\right) / \mathrm{A}_{0} \times 100 \%$ (where $\mathrm{A}_{0}$ the initial peak area before irradiation and $\mathrm{A}_{t}$ the peak area of the functional groups at time $t$ ). The conversion $C$ measured here is not throughout the whole sample thickness as the penetration depth of infrared beam into the sample is ca. $0.5-3 \mu \mathrm{m}$ for the ATR-IR spectroscopy, which is similar to the light penetration, and can thus be used to evaluate the photoinitiation ability of the relevant DAAQ-based photoinitiating systems. The well-known blue-light-sensitive camphorquinone-based photoinitiating system was used as a reference.

\section{RESULTS AND DISCUSSION}

\section{1/ UV-vis Absorption of DAAQs}

The UV-vis absorption of DAAQs (i.e. AHAQ, 14-DAAQ, and 15-DAAQ) in acetonitrile and their overlap with emission spectra of blue $(455 \mathrm{~nm})$, green $(518 \mathrm{~nm})$, yellow (594 nm), and red (635 nm) LEDs are demonstrated in Figure 1, while their absorption maxima $\left(\lambda_{\max }\right)$ and extinction coefficients $(\varepsilon)$ at $\lambda_{\max }$ and at the maximum emission wavelengths of different LEDs are summarized in Table 1 . As illustrated, AHAQ, 14-DAAQ, and 15-DAAQ exhibit maximum absorption $\left(\lambda_{\max }\right)$ at $522 \mathrm{~nm}, 544 \mathrm{~nm}$ and $479 \mathrm{~nm}$, and their corresponding extinction coefficients $\left(\varepsilon_{\max }\right)$ are $11100 \mathrm{M}^{-1} \mathrm{~cm}^{-1}, 12800 \mathrm{M}^{-1} \mathrm{~cm}^{-1}$, 
and $9300 \mathrm{M}^{-1} \mathrm{~cm}^{-1}$ respectively. Interestingly, all three DAAQs demonstrate satisfactory overlap with the emission spectra of the blue (455 nm) and green $(518 \mathrm{~nm})$ LEDs, i.e. the extinction coefficients at the maximum emission wavelengths of the LEDs are higher than $2000 \mathrm{M}^{-1} \mathrm{~cm}^{-1}$ (Table 1). In addition, the light absorption of 14-DAAQ matches well with the emission wavelength of the yellow LED (594 $\mathrm{nm}$ ) and the extinction coefficient at $594 \mathrm{~nm}$ is $8800 \mathrm{M}^{-1} \mathrm{~cm}^{-1}$. Moreover, it also demonstrates the light absorption at the maximum emission wavelength of the red LED (636 nm), but the relevant extinction coefficient is not high $\left(530 \mathrm{M}^{-1} \mathrm{~cm}^{-1}\right)$. Nonetheless, 14-DAAQ can absorb light from all the investigated LEDs. For 15-DAAQ, the slightly higher baseline of the UV-vis absorption spectrum can be ascribed to its lower solubility in acetonitrile compared to AHAQ and 14-DAAQ. 15-DAAQ can be properly dissolved in the monomer EPOX (Figure S1).
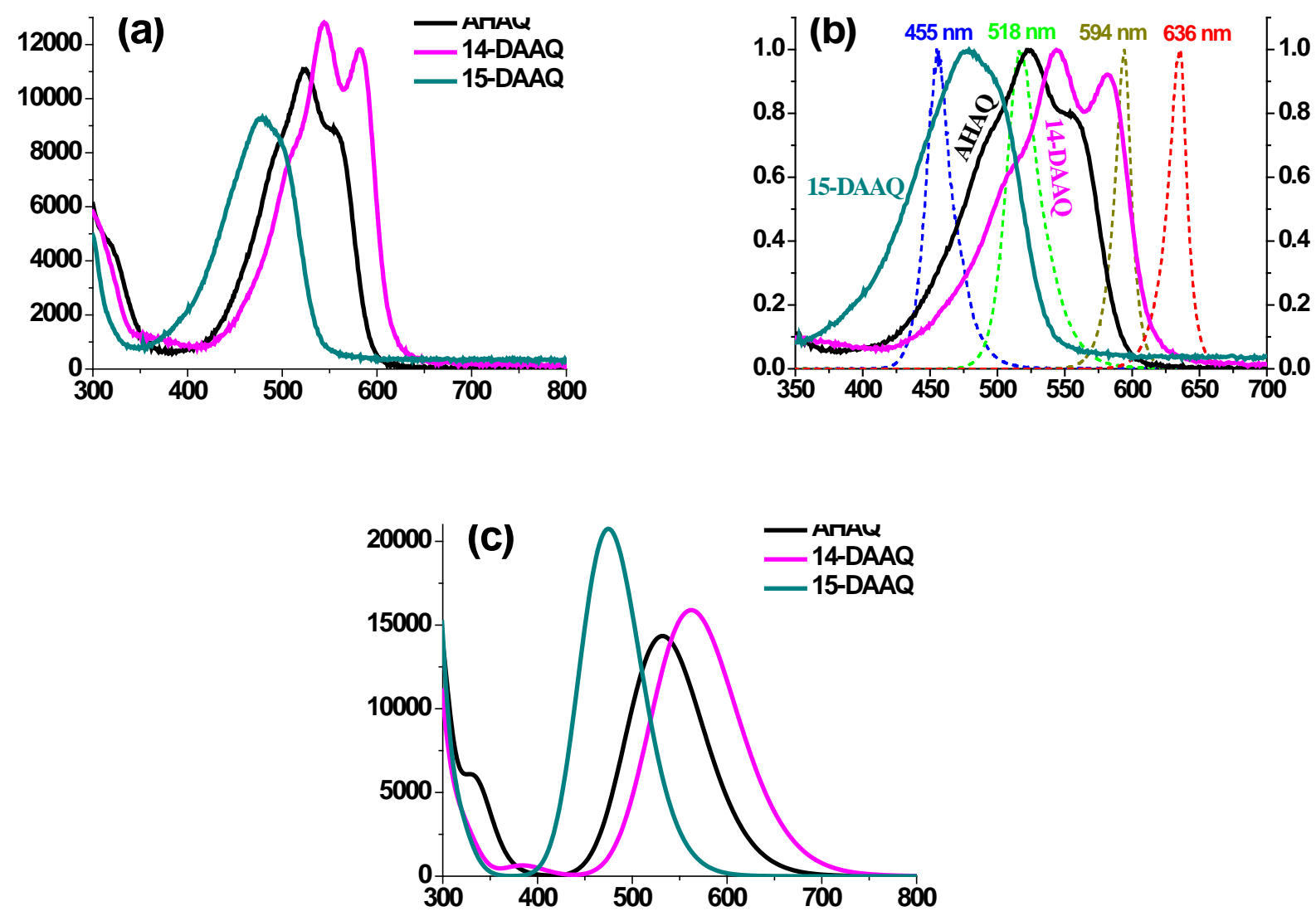
Figure 1. (a) UV-vis absorption spectra of AHAQ, 14-DAAQ, and 15-DAAQ in acetonitrile; (b) their overlap with the emission spectra of blue $(455 \mathrm{~nm})$, green $(518 \mathrm{~nm})$, yellow $(594 \mathrm{~nm})$, and red $(636 \mathrm{~nm})$ LEDs; (c) adjusted simulated UV-vis absorption spectra of AHAD, 14-DAAQ, and 15-DAAQ.

Table 1. Light absorption properties of AHAQ, 14-DAAQ and 15-DAAQ: maximum absorption wavelengths $\lambda_{\max }$, extinction coefficients at $\lambda_{\max }$ and at the maximum emission wavelengths of the different LED bulbs.

\begin{tabular}{ccccccc}
\hline & $\begin{array}{c}\lambda_{\max } \\
(\mathrm{nm})\end{array}$ & $\begin{array}{c}\varepsilon_{\max } \\
\left(\mathrm{M}^{-1} \mathrm{~cm}^{-1}\right)\end{array}$ & $\begin{array}{c}\varepsilon_{455 \mathrm{~nm}} \\
\left(\mathrm{M}^{-1} \mathrm{~cm}^{-1}\right)^{*}\end{array}$ & $\begin{array}{c}\varepsilon_{518 \mathrm{~nm}} \\
\left(\mathrm{M}^{-1} \mathrm{~cm}^{-1}\right)^{*}\end{array}$ & $\begin{array}{c}\varepsilon_{594 \mathrm{~nm}} \\
\left(\mathrm{M}^{-1} \mathrm{~cm}^{-1}\right)^{*}\end{array}$ & $\begin{array}{c}\varepsilon_{636 \mathrm{~nm}} \\
\left(\mathrm{M}^{-1} \mathrm{~cm}^{-1}\right)^{*}\end{array}$ \\
\hline AHAQ & 522 & 11100 & 3300 & 10700 & 990 & $\sim 0$ \\
14-DAAQ & 544 & 12800 & 2100 & 8600 & 8800 & 530 \\
15-DAAQ & 479 & 9300 & 7400 & 4900 & $\sim 360$ & $\sim 300$ \\
\hline
\end{tabular}

* For maximum emission wavelengths of different LEDs

The absorption spectra were also simulated using time-dependent density functional theory (TDDFT). As found in previous studies, ${ }^{47}$ the M06-2X functional is found to overestimate the $\lambda_{\max }$ values by a factor of approximately 1.2. Accounting for this overestimation gives simulated UV-vis spectra (Figure 1) in good agreement with the experimental spectra. The $S_{1}$ states for AHAQ, 14-DAAQ, and 15-DAAQ are each dominated by $\pi \pi^{*}$ transitions, shown in Figure 2. The $\epsilon_{\max }$ value for 15-DAAQ is also overestimated, however as the overall peak position is consistent with experiment it is inconsequential.

HOMO $(\pi)$




\begin{tabular}{|c|c|c|r|}
\hline & AHAQ & 14-DAAQ & 15-DAAQ \\
\hline
\end{tabular}

Figure 2. Orbitals involved in $\mathrm{S}_{0} \rightarrow \mathrm{S}_{1}, \pi \pi^{*}$ transitions of AHAQ, 14-DAAQ, and 15-DAAQ.

\section{2/ Photoinitiation Mechanism of Disubstituted Aminoanthraquinone-based Photoinitiating Systems}

The photoinitiation mechanism of the investigated disubstituted aminoanthraquinone-based photoinitiating systems DAAQs/Iod was studied using a variety of approaches. The fluorescence emission spectra (related to their excited singlet states) of AHAQ, 14-DAAQ, and 15-DAAQ are illustrated in Figure S2 in the supporting information, and their quantum yields in acetonitrile are 0.0071, 0.0034 , and 0.0033 respectively. Interestingly, the fluorescence of 14-DAAQ is dramatically quenched by the addition of Iod as shown in Figure 3 (a), and the interaction rate constant of ${ }^{1} 14-\mathrm{DAAQ} / \mathrm{Iod}$ was determined (i.e. $k_{q} \sim 6.0 \times 10^{9} \mathrm{M}^{-1} \mathrm{~s}^{-1}$ ) from the Stern-Volmer treatment [Figure 3 (b); fluorescence lifetime of 14-DAAQ $\left.\tau_{0} \sim 3 \mathrm{~ns}\right]$. Similarly, $k_{q} \sim 1.0 \times 10^{9} \mathrm{M}^{-1} \mathrm{~s}^{-1}$ was determined for ${ }^{1} 15-\mathrm{DAAQ} /$ Iod interaction [Figure S3 (b) and (c); fluorescence lifetime of 15-DAAQ $\tau_{0} \sim 3 \mathrm{~ns}$ ]. These demonstrate the occurrence of electron transfer between the excited singlet state of 14-DAAQ (or 15-DAAQ) and the ground-state of Iod, and that the process is diffusion-controlled. However, no obvious fluorescence quenching was observed for the AHAQ with the addition of Iod [Figure S3 (a)] indicating the low efficiency of the interaction of ${ }^{1} \mathrm{AHAQ} / \mathrm{Iod}$. More interestingly, the electron transfer quantum yields $\left[\Phi_{\mathrm{eT}}=k_{q} \tau_{0}[\mathrm{Iod}] /(1\right.$ $\left.+k_{q} \tau_{0}[\mathrm{Iod}]\right)^{1}$; where $[\mathrm{Iod}]=4.7 \times 10^{-2} \mathrm{M}$ in formulations $]$ of ${ }^{1} 14$-DAAQ/Iod $\left(\Phi_{\mathrm{eT}}=0.46\right)$ and ${ }^{1} 15-$ DAAQ/Iod $\left(\Phi_{\mathrm{eT}}=0.12\right)$ indicate that the photochemical reactivity of ${ }^{1} 14$-DAAQ/Iod is higher than that of ${ }^{1} 15-\mathrm{DAAQ} / \mathrm{Iod}$. 

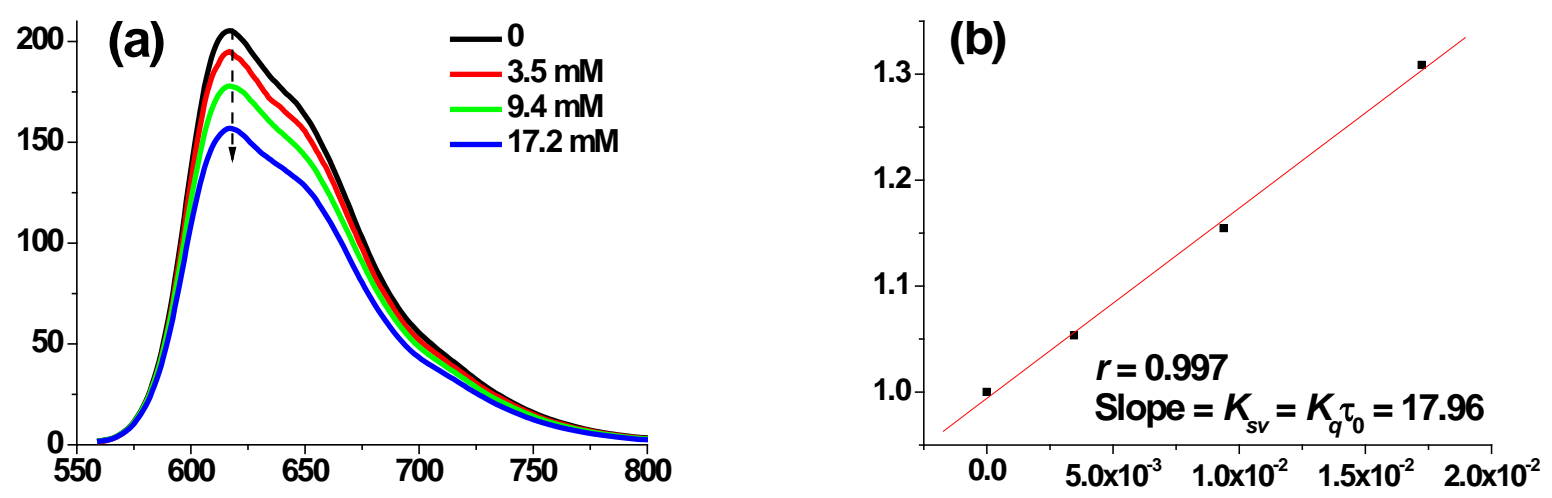

Figure 3. (a) Fluorescence spectra of 14-DAAQ as a function of [Iod] in acetonitrile and (b) the relevant Stern-Volmer plot.

The excited singlet state of aminoanthraquinone derivatives may undergo intersystem crossing to yield the excited triplet states, ${ }^{56}$ and the relevant triplet quantum yields are dependent on the number of substituents, their position, and the solvent. ${ }^{57,58}$ It has been reported that the triplet quantum yields of 14 DAAQ and 15-DAAQ in toluene can be determined using laser flash photolysis (LFP), ${ }^{57}$ but there is no observable triplet formation in the LFP of the investigated DAAQs in acetonitrile in the 400-700 nm range of our study, which can be ascribed to the different polarity of the solvents used. ${ }^{57,58}$

Modelling the electron transfer mechanism for different species of the anthraquinones provides insight into the observed differences in photoinitiating activity. Figure 4 summarises the electron-transfer mechanism for the photo-excited AHAQ, 14-DAAQ, and 15-DAAQ molecules. Table 2 highlights some key energies along the reaction coordinates of AHAQ, 14-DAAQ, and 15-DAAQ. 


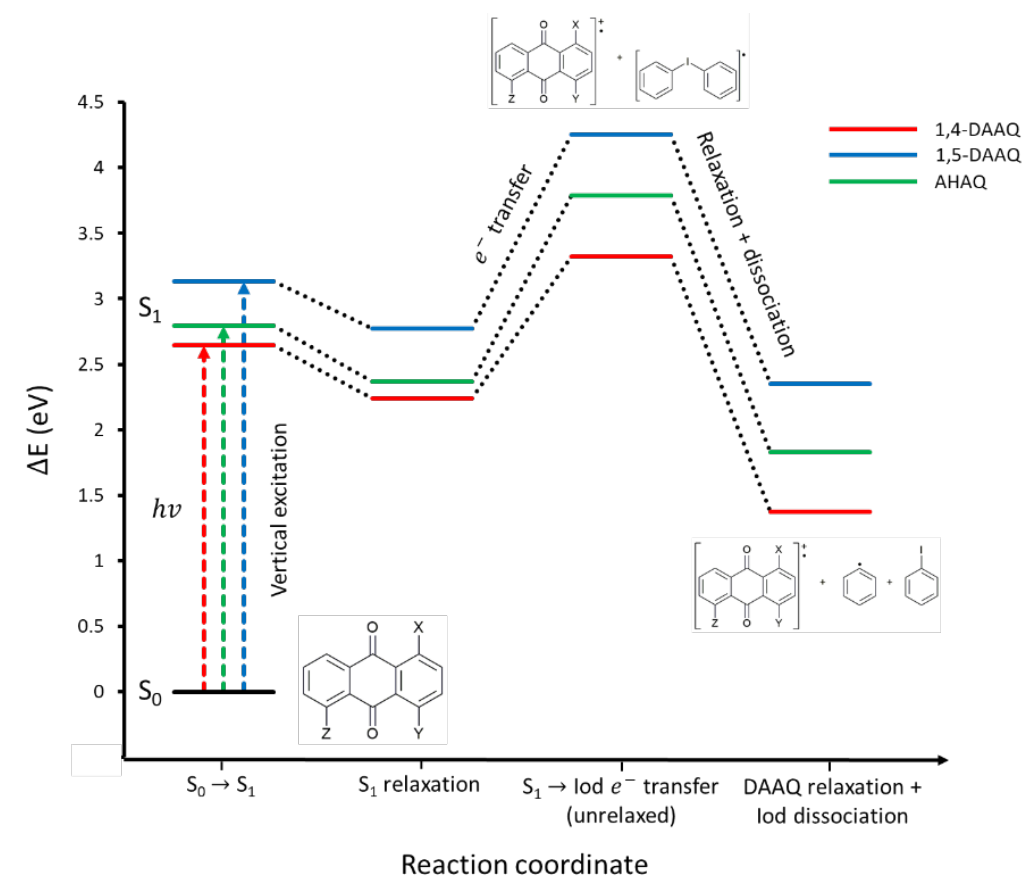

Figure 4. Energy level diagram for possible internal energy/electron transfer processes taking place with 14-DAAQ, 15-DAAQ, and AHAQ

Table 2. Energies for the energy and electron transfer processes $(\mathrm{eV})$ shown in Figure 4, and the change in Gibbs free energy $(\mathrm{eV})$ for the overall excited state electron transfer reaction.

\begin{tabular}{cccc}
\hline DAAQs & $\mathrm{S}_{0} \rightarrow \mathrm{S}_{1}$ & $\begin{array}{c}\mathrm{S}_{1} \rightarrow \text { Iod } e^{-} \\
\text {transfer } \\
\text { (unrelaxed) }\end{array}$ & $\Delta \mathrm{G}\left(\mathrm{S}_{1} \rightarrow \operatorname{Iod}_{\text {relax }}\right)$ \\
\hline AHAQ & +2.7971 & +0.8148 & -1.0685 \\
14-DAAQ & +2.6464 & +0.5101 & -1.3777 \\
15-DAAQ & +3.1338 & +1.0032 & -0.8724 \\
\hline
\end{tabular}

Figure 4 and Table 2 show that 14-DAAQ exhibits the lowest energy pathway to electron transfer to the Iod species, with a $\mathrm{S}_{1} \rightarrow$ Iod $e^{-}$transfer (unrelaxed) $\Delta \mathrm{E}$ of $+0.51 \mathrm{eV}$, almost $0.5 \mathrm{eV}$ lower than for 15DAAQ; as well this, at -1.38 eV 14-DAAQ exhibits a greater thermodynamic favourability for the overall excited state electron transfer process shown in Equations 2 and 3. While less efficient, Figure 4 also suggests that both 15-DAAQ and AHAQ should also undergo electron transfer with Iod, whereas experiments show that this is not the case for AHAQ. While both 15-DAAQ and AHAQ suffer from both 
a relatively high barrier and low thermodynamic favourability to electron transfer, the 15-DAAQ triplet excited state is near to the $\mathrm{S}_{1}$ state allowing intersystem crossing (Figure $\mathrm{S} 4$ ). This may extend the excited state lifetime allowing electron transfer to compete with fluorescence. In contrast the triplet state is less energetically accessible for AHAQ (+0.54 eV above $S_{1}$ versus +0.22 for $\left.15-\mathrm{DAAQ}\right)$. The combined result of these two effects is that fluorescence outcompetes all other processes in AHAQ, preventing electron transfer to Iod.

Based on the above information, the interaction between DAAQs and Iod during the light irradiation can be depicted in the reactions (1) - (3) as follows.

$$
\begin{aligned}
& \mathrm{DAAQ} \rightarrow{ }^{1} \mathrm{DAAQ}(h v) \\
& { }^{1} \mathrm{DAAQ} \rightarrow{ }^{3} \mathrm{DAAQ} \\
& { }^{1,3} \mathrm{DAAQ}+\mathrm{Ph}_{2} \mathrm{I}^{+} \rightarrow \mathrm{DAAQ}^{\bullet+}+\mathrm{Ph}_{2} \mathrm{I}^{\bullet} \\
& \mathrm{Ph}_{2} \mathrm{I}^{\bullet} \rightarrow \mathrm{Ph}^{\bullet}+\mathrm{Ph}-\mathrm{I}
\end{aligned}
$$

The interaction of DAAQs/Iod under green LED irradiation can be qualitatively investigated using steady state photolysis. ${ }^{6}$ As demonstrated in Figure 5, the UV-vis absorption of DAAQs/Iod decreased during irradiation with light. Interestingly, isobestic points were observed at 452/588 nm, 481/610 nm, and 423/520 nm for AHAQ/Iod, 14-DAAQ/Iod, and 15-DAAQ/Iod respectively, which indicates that no secondary reactions occurred in the reaction (2). The much faster photolysis of 14-DAAQ/Iod than those of the other two systems can be ascribed to its better reactivity during the light irradiation, which is also in agreement with the results of the fluorescence quenching. 

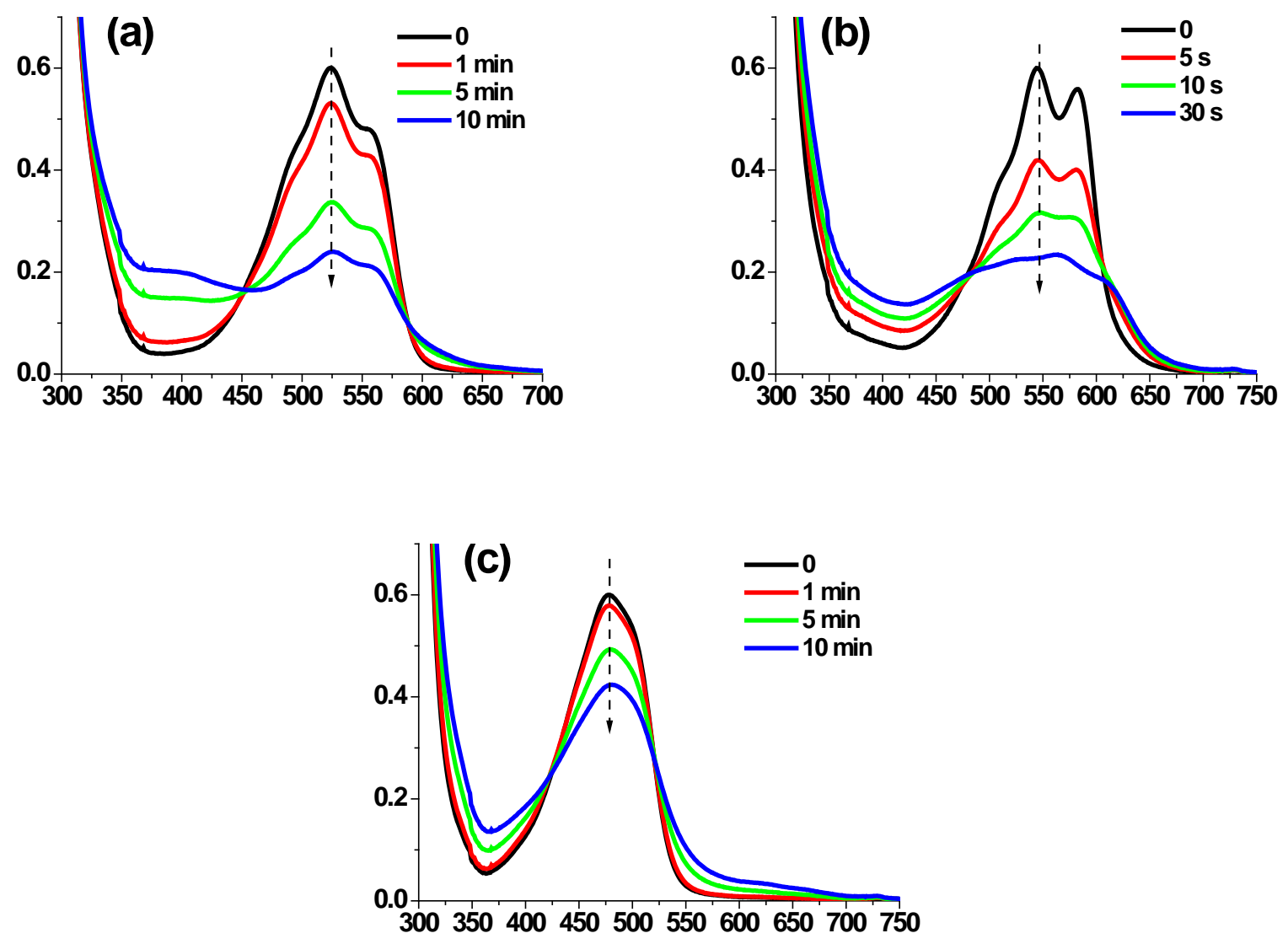

Figure 5. Steady state photolysis of (a) AHAQ/Iod, (b) 14-DAAQ/Iod, and (c) 15-DAAQ/Iod in acetonitrile ([Iod] = 15 mM); UV-vis spectra recorded at different irradiation time; Green LED@518 nm irradiation $\left(60 \mathrm{~mW} \mathrm{~cm}^{-2}\right)$.

More interestingly, the generated radicals from the electron transfer in the DAAQ/Iod systems under light irradiation can be determined using the ESR spin trapping technique. Specifically, the hyperfine splitting constants (HFS) for both the nitrogen $\left(\mathrm{a}_{\mathrm{N}}\right)$ and the hydrogen $\left(\mathrm{a}_{\mathrm{H}}\right)$ of the PBN/radical adducts can be used to determine the types of radicals. Precisely, $\mathrm{a}_{\mathrm{N}}=14.3 \mathrm{G}$ and $\mathrm{a}_{\mathrm{H}}=2.2 \mathrm{G}$ were measured in the 15-DAAQ/Iod system (Figure 6), which can be assigned to PBN/phenyl radical adducts. $^{59,60}$ This further confirmed the generation of phenyl radicals ( $\mathrm{Ph}^{\bullet}$ ) in reactions (1) - (3) as indicated above. 


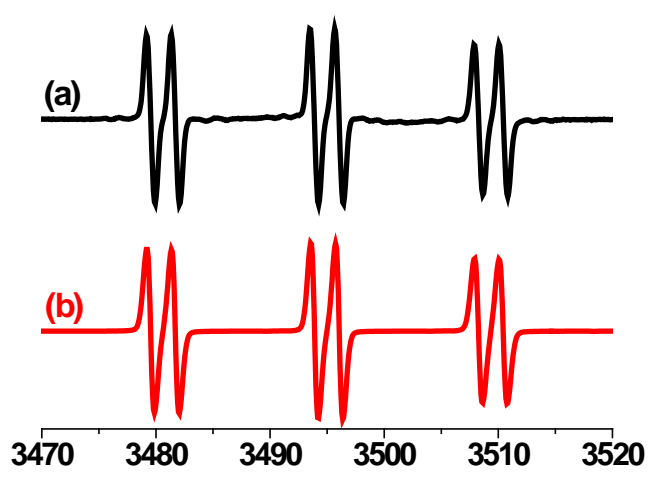

Figure 6. ESR spectra of the radicals generated in 15-DAAQ/Iod combination upon the blue LED exposure and trapped by PBN in tert-butylbenzene: (a) experimental and (b) simulated spectra.

\section{3/ Photoinitiation Ability of Disubstituted Aminoanthraquinone-based Photoinitiating Systems for Cationic Polymerization}

As expected, the generated DAAQs-derived cations (DAAQs ${ }^{\bullet+}$ ) from the DAAQs/Iod systems (reactions (1) - (3)) under light irradiation can initiate the cationic photopolymerization of EPOX. And the photoinitiation ability of these systems can be associated with the relevant light absorption properties of DAAQs, photoreactivity of DAAQs/Iod, and the structures of DAAQs ${ }^{\bullet+}$. As shown in Figure 7 and Table 3, all the DAAQs/Iod systems is capable of initiating the cationic polymerization of EPOX upon exposure to blue $(455 \mathrm{~nm})$ or green $(518 \mathrm{~nm})$ LED, which is in agreement with the satisfactory overlap of the light absorption of the studied DAAQs with the emission spectra of the blue (455 $\mathrm{nm}$ ) and green (518 nm) LEDs. Specifically, 65\% 77\% epoxy conversions were obtained when using the 14DAAQ/Iod or 15-DAAQ/Iod photoinitiating systems for $800 \mathrm{~s}$ of photopolymerization under blue or green LED. However, the initiation ability of AHAQ/Iod was relatively lower (i.e. < 30\% of epoxy conversions), which can be ascribed to the lack of obvious fluorescence quenching of AHAQ/Iod system as indicated above. More interestingly, 14-DAAQ/Iod was also efficient for the cationic polymerization 
of EPOX under yellow (594 nm) and red (636 nm) LEDs, and > 55\% of epoxy conversions can be achieved after $800 \mathrm{~s}$ of photopoymerization. Among the investigated DAAQs/Iod systems, 14DAAQ/Iod is the only system that can work upon the exposure to all the LEDs: this is in line with the panchromatic light absorption of 14-DAAQ and the high photochemical reactivity of 14-DAAQ/Iod. Notably, the well-known commercial photoinitiator camphorquinone (CQ) based system CQ/Iod was inefficient under the same conditions which underlines the high performance of the investigated DAAQbased systems. Furthermore, the addition of NVK into the DAAQs/Iod systems can promote their photoinitiation ability due to the NVK additive effect ${ }^{61}$ as depicted in reactions (4) - (5), with the produced $\mathrm{Ph}-\mathrm{NVK}^{+}$is efficient for the cationic photopolymerization.

$$
\begin{aligned}
& \mathrm{Ph}^{\bullet}+\mathrm{NVK} \rightarrow \mathrm{Ph}^{-N V K}{ }^{\bullet} \\
& \mathrm{Ph}^{-N V K}{ }^{\bullet}+\mathrm{Ph}_{2} \mathrm{I}^{+} \rightarrow \mathrm{Ph}^{-N_{V K}}+\mathrm{Ph}^{\bullet}+\mathrm{Ph}-\mathrm{I}
\end{aligned}
$$

For instance, $>80 \%$ epoxy conversions were obtained when using the 15-DAAQ/Iod/NVK system for $800 \mathrm{~s}$ of photopolymerization under blue or green LED. Markedly, even $>75 \%$ of conversions were attained under yellow or red LED with 14-DAAQ/Iod/NVK system, which is unusual for the cationic photopolymerization of EPOX under the irradiation of such long-wavelength light. More interestingly, 14-DAAQ (or 15-DAAQ)/Iod/NVK system was quite stable in the formulation as the photoinitiation ability did not change significantly after one-week storage at room temperature (Table 3). 

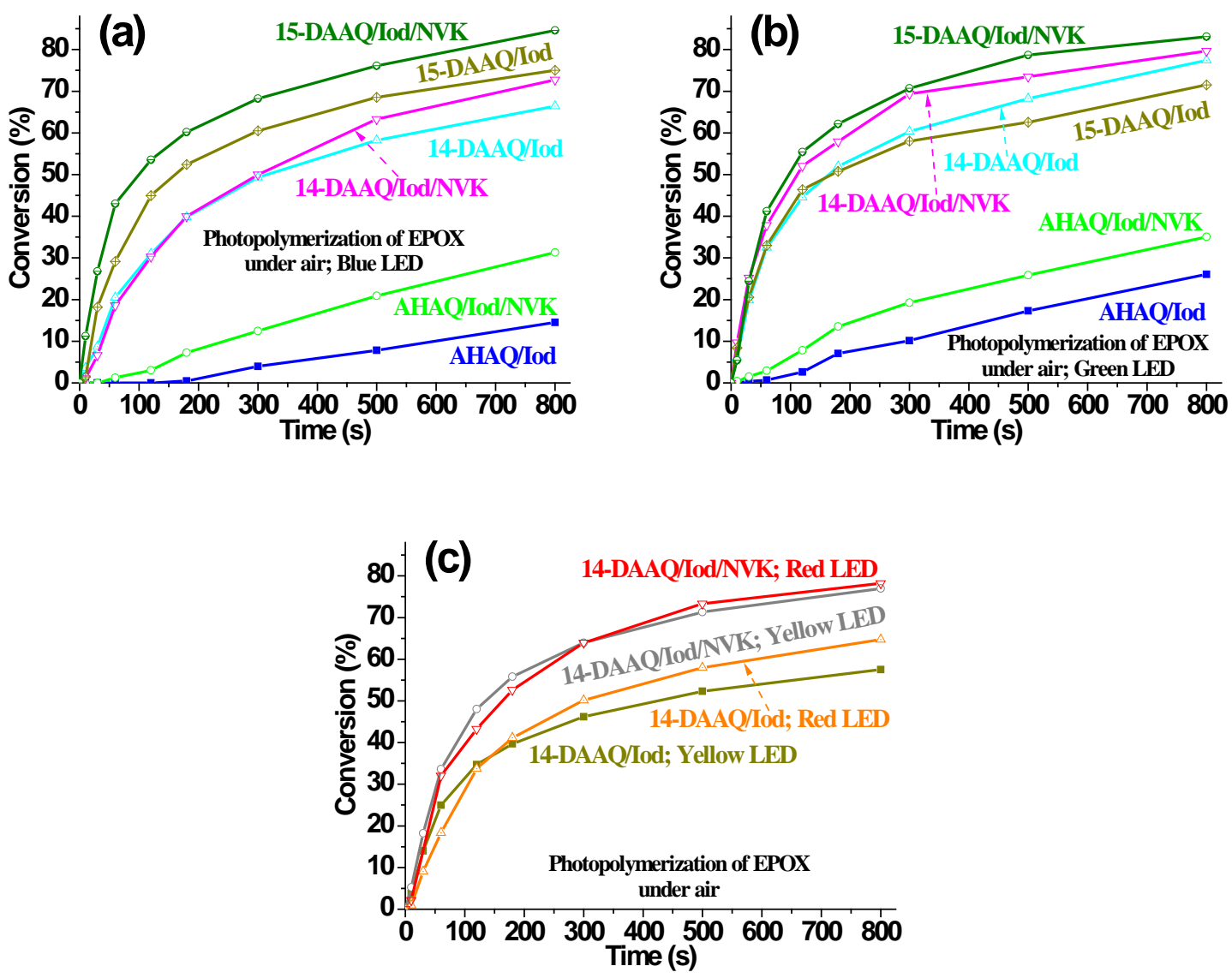

Figure 7. Photopolymerization profiles of EPOX under air in the presence of AHAQ, 14-DAAQ, or 15DAAQ-based PISs upon exposure to (a) Blue LED@455 nm (60 mW cm²); (b) Green LED@518 nm (60 mW cm $\left.{ }^{-2}\right)$; (c) Yellow LED@594 nm (30 mW cm $\left.{ }^{-2}\right)$ and Red LED@636 nm $\left(60 \mathrm{~mW} \mathrm{~cm}{ }^{-2}\right)$. AHAQ, 14-DAAQ, or 15-DAAQ: 0.5 wt\%; Iod: 2 wt $\%$; NVK: 3 wt\%.

Table 3. Epoxy conversions of photopolymerization of EPOX obtained under air upon exposure to different household LED devices for $800 \mathrm{~s}$ in the presence of DAAQs based PISs (DAAQs or CQ: 0.5 wt\%; Iod: 2 wt\%; NVK: 3 wt\%).

\begin{tabular}{ccccc}
\hline PIS & LED & LED & LED & LED \\
& $(455 \mathrm{~nm})$ & $(518 \mathrm{~nm})$ & $(594 \mathrm{~nm})$ & $(636 \mathrm{~nm})$ \\
\hline AHAQ/Iod & $15 \%$ & $26 \%$ & $\mathrm{np}$ & $\mathrm{np}$ \\
AHAQ/Iod/NVK & $31 \%$ & $35 \%$ & $\mathrm{np}$ & $\mathrm{np}$ \\
14-DAAQ/Iod & $66 \%$ & $77 \%$ & $58 \%$ & $65 \%$ \\
14-DAAQ/Iod/NVK & $73 \% \mid 74 \%{ }^{\mathrm{a}}$ & $80 \%$ & $77 \%$ & $78 \%$ \\
15-DAAQ/Iod & $75 \%$ & $72 \%$ & $\mathrm{np}$ & $\mathrm{np}$ \\
15-DAAQ/Iod/NVK & $85 \% \mid 83 \%^{\mathrm{a}}$ & $83 \%$ & $\mathrm{np}$ & $\mathrm{np}$ \\
CQ/Iod & $\mathrm{np}$ & $\mathrm{np}$ & $\mathrm{np}$ & $\mathrm{np}$ \\
\hline
\end{tabular}

np: no photopolymerization.

a: after one-week storage 
DAAQ-based photoinitiating systems were also capable of initiating cationic photopolymerization of divinyl ether DVE-3 as shown in reactions (6) - (7) and Figure 8. Specifically, 14-DAAQ/Iod combination can act as a multicolor photoinitiating system, and $78 \%, 74 \%, 61 \%$, and $81 \%$ of double bond conversions of DVE-3 can be achieved when the photopolymerization reactions were conducted under the irradiation of blue, green, yellow, and red LEDs respectively [Figure 8 (a)]. In addition, 15DAAQ based photoinitiating systems can also work under blue and green LEDs for the polymerization of DVE-3 as illustrated in Figure 8 (b), and 78\% - 87\% of double bond conversions of DVE-3 was attained. The addition of NVK into the photoinitiating systems did not dramatically improve the polymerization profiles, which can be attributed to the fact that the 15-DAAQ/Iod system was already quite efficient to initiate the cationic polymerization of DVE-3 and there was no significant room for the further improvement of the performance.

$$
\begin{aligned}
& \mathrm{Ph}^{\bullet}+\mathrm{R}^{\prime}-\mathrm{O}-\mathrm{CH}=\mathrm{CH}_{2} \rightarrow \mathrm{R}^{\prime}-\mathrm{O}-\mathrm{CH}^{\bullet}-\mathrm{CH}_{2}-\mathrm{Ph} \\
& \mathrm{R}^{\prime}-\mathrm{O}-\mathrm{CH} \mathrm{CH}^{\bullet}-\mathrm{CH}_{2}-\mathrm{Ph}+\mathrm{Ph}_{2} \mathrm{I}^{+} \rightarrow \mathrm{R}^{\prime}-\mathrm{O}-\mathrm{CH}^{+}-\mathrm{CH}_{2}-\mathrm{Ph}\left(\text { i.e. Ph-DVE-3 }{ }^{+}\right)+\mathrm{Ph}^{\bullet}+\mathrm{Ph}-\mathrm{I}
\end{aligned}
$$
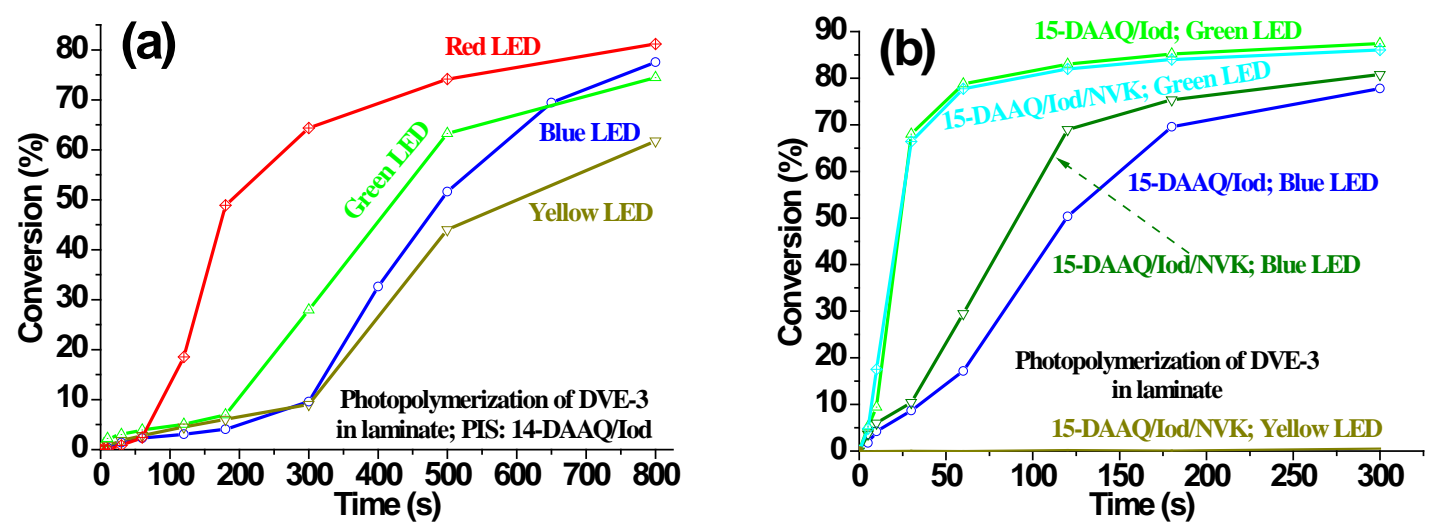

Figure 8. Photopolymerization profiles of DVE-3 in laminate in the presence of DAAQ-based PISs (DAAQ: 0.5 wt\%; Iod: 2 wt\%; NVK: 3 wt\%) upon exposure to different LEDs [i.e. Blue LED@455 nm (60 mW cm $\left.{ }^{-2}\right)$, Green LED@518 nm (60 mW cm$\left.{ }^{-2}\right)$, Yellow LED@594 nm $\left(30 \mathrm{~mW} \mathrm{~cm}{ }^{-2}\right)$ and Red LED@636 nm $\left.\left(60 \mathrm{~mW} \mathrm{~cm}{ }^{-2}\right)\right]$. 


\section{CONCLUSION:}

The investigation of photoinitiation mechanism of the studied three disubstituted aminoanthraquinone-based photoinitiating systems (PISs) revealed that 14-DAAQ exhibited the highest photoreactivity towards Iod while AHAQ demonstrated the lowest efficiency under the LED irradiation. Phenyl radicals are produced in the initiation process, as confirmed for instance in the 15-DAAQ/Iod combination through the ESR-ST experiments in which DAAQ-based cations DAAQ ${ }^{\bullet+}$ are observed. The types and positions of substituents of the disubstituted aminoanthraquinone derivatives play a significant role in their photoinitiation ability. Specifically, in line with the results of the photoinitiation mechanism study, 14-DAAQ/additives systems can act as efficient multicolour PISs as they were capable of initiating cationic photopolymerization of epoxide and divinyl ether under various LEDs with different emission wavelengths, i.e. blue, green, yellow, and red LEDs, while AHAQ- and 15-DAAQ-based photoinitiating systems can only work under the irradiation of blue and green LEDs. Interestingly, even > $80 \%$ of epoxy or double bond conversions can be achieved for the photopolymerization of epoxide and divinyl ether monomers when using the 14-DAAQ or 15-DAAQ based photoinitiating systems. The high efficiency of the 14-DAAQ or 15-DAAQ based photoinitiating systems can endow them with the potential applications in 3D printing and fabrication of photopolymer-based materials. The ability of the DAAQ-based photoinitiating systems for free radical photopolymerization will be presented in forthcoming papers.

\section{ASSOCIATED CONTENT}

UV-vis absorption spectra of EPOX and 15-DAAQ in EPOX (Figure S1); fluorescence emission spectra of DAAQs (Figure S2); fluorescence quenching of AHAQ and 15-DAAQ by Iod (Figure S3); triplet state 
energies relative to $\mathrm{S}_{1}$ state for DAAQs (Figure $\mathrm{S} 4$ ); raw computational data. This information is available free of charge via the Internet.

\section{Corresponding Authors}

*E-mail: pu.xiao@anu.edu.au (P. X.); michelle.coote@anu.edu.au (M.L.C.)

\section{Notes}

The authors declare no competing financial interest.

\section{ACKNOWLEDGMENTS:}

P. X. acknowledges funding from the Australian Research Council Future Fellowship (FT170100301). MLC gratefully acknowledges a Georgina Sweet ARC Laureate Fellowship (FL170100041) and generous allocations of supercomputing time on the National Facility of the Australian National Computational Infrastructure.

\section{REFERENCES:}

1. Fouassier, J. P.; Lalevée, J., Photoinitiators for Polymer Synthesis-Scope, Reactivity, and Efficiency. Weinheim: Wiley-VCH Verlag GmbH \& Co KGaA, , 2012.

2. Fouassier, J. P., Photoinitiator, Photopolymerization and Photocuring: Fundamentals and Applications. New York/Munich/Vienna: Hanser Publishers, 1995.

3. Crivello, J. V.; Dietliker, K., Photoinitiators for Free Radical, Cationic and Anionic Photopolymerization, 2nd edition. Chichester: John Wiley \& Sons: 1998.

4. Scranton, A. B.; Bowman, C. N.; Peiffer, R. W., Photopolymerization: Fundamentals and Applications. ACS Symp. Ser. 673; ACS, Washington, DC, USA: 1997.

5. Allen, N. S., Photochemistry and Photophysics of Polymeric Materials. Wiley: Hoboken, NJ, USA: 2010.

6. Xiao, P.; Zhang, J.; Dumur, F.; Tehfe, M. A.; Morlet-Savary, F.; Graff, B.; Gigmes, D.; Fouassier, J. P.; Lalevée, J. Visible light sensitive photoinitiating systems: Recent progress in cationic and radical photopolymerization reactions under soft conditions. Prog. Polym. Sci. 2015, 41, 32-66. 
7. Shi, S.; Croutxé-Barghorn, C.; Allonas, X. Photoinitiating systems for cationic photopolymerization: Ongoing push toward long wavelengths and low light intensities. Prog. Polym. Sci. 2017, 65, 1-41.

8. Tasdelen, M. A.; Yagci, Y. Benzodioxinone Photochemistry in Macromolecular Science: Progress, Challenges, and Opportunities. ACS Macro Lett. 2017, 6, 1392-1397.

9. Lauer, A.; Fast, D. E.; Steinkoenig, J.; Kelterer, A.-M.; Gescheidt, G.; Barner-Kowollik, C. Wavelength-Dependent Photochemical Stability of Photoinitiator-Derived Macromolecular Chain Termini. ACS Macro Lett. 2017, 6, 952-958.

10. Ciftci, M.; Yoshikawa, Y.; Yagci, Y. Living Cationic Polymerization of Vinyl Ethers through a Photoinduced Radical Oxidation/Addition/Deactivation Sequence. Angew. Chem. Int. Ed. 2017, 56, 519523.

11. Ambrosi, A.; Pumera, M. 3D-printing technologies for electrochemical applications. Chem. Soc. Rev. 2016, 45, 2740-2755.

12. Zhang, J.; Xiao, P. 3D printing of photopolymers. Polym. Chem. 2018, 9, 1530-1540.

13. Barner-Kowollik, C.; Bastemeyer, M.; Blasco, E.; Patrick, M.; Delaittre, G.; Richter, B.; Wegener, M. 3D Laser Micro- and Nano-Printing: Challenges for Chemistry. Angew. Chem. Int. Ed. 2017, 56, 15828-15845.

14. Donderwinkel, I.; van Hest, J. C. M.; Cameron, N. R. Bio-inks for 3D bioprinting: recent advances and future prospects. Polym. Chem. 2017, 8, 4451-4471.

15. Stansbury, J. W.; Idacavage, M. J. 3D printing with polymers: Challenges among expanding options and opportunities. Dent. Mater. 2016, 32, 54-64.

16. Ligon-Auer, S. C.; Schwentenwein, M.; Gorsche, C.; Stampfl, J.; Liska, R. Toughening of photocurable polymer networks: a review. Polym. Chem. 2016, 7, 257-286.

17. Xing, J.-F.; Zheng, M.-L.; Duan, X.-M. Two-photon polymerization microfabrication of hydrogels: an advanced 3D printing technology for tissue engineering and drug delivery. Chem. Soc. Rev. 2015, 44, 5031-5039.

18. Gorsche, C.; Seidler, K.; Knaack, P.; Dorfinger, P.; Koch, T.; Stampfl, J.; Moszner, N.; Liska, R. Rapid formation of regulated methacrylate networks yielding tough materials for lithography-based 3D printing. Polym. Chem. 2016, 7, 2009-2014.

19. Pawar, A. A.; Halivni, S.; Waiskopf, N.; Ben-Shahar, Y.; Soreni-Harari, M.; Bergbreiter, S.; Banin, U.; Magdassi, S. Rapid Three-Dimensional Printing in Water Using Semiconductor-Metal Hybrid Nanoparticles as Photoinitiators. Nano Lett. 2017, 17, 4497-4501.

20. Huang, L.; Jiang, R.; Wu, J.; Song, J.; Bai, H.; Li, B.; Zhao, Q.; Xie, T. Ultrafast Digital Printing toward 4D Shape Changing Materials. Adv. Mater. 2017, 29, 1605390 (1-6).

21. Han, Y.; Wang, F.; Lim, C. Y.; Chi, H.; Chen, D.; Wang, F.; Jiao, X. High-Performance NanoPhotoinitiators with Improved Safety for 3D Printing. ACS Appl. Mater. Interfaces 2017, 9, 3241832423.

22. Fouassier, J.-P.; Lalevée, J., Photoinitiators for Polymer Synthesis-Scope, Reactivity, and Efficiency. Wiley-VCH Verlag GmbH \& Co. KGaA: 2012.

23. Crivello, J. V., Photoinitiators for Free Radical, Cationic and Anionic Photopolymerization, 2nd edition. John Wiley \& Sons: Chichester, 1998.

24. Neckers, D. C.; Jager, W., Photoinitiation for Polymerization: UV and EB at the Millenium. John Wiley \& Sons: Chichester, 1999. 410 pp.

25. Davidson, S., Exploring the Science, Technology and Application of UV and EB Curing. Sita Technology Ltd: London, 1999. 290 pp.

26. Dietliker, K., A Compilation of Photoinitiators commercially available for UV today. Sita Technology Ltd: Edinburgh, London, 2002. 250 pp.

27. Belfied, K. D.; Crivello, J. V., Photoinitiated Polymerization. ACS Symp series 847. Washington DC: Am Chem Soc, , 2003. 
28. Allen, N. S., Photochemistry and photophysics of polymer materials. Wiley: USA, 2010.

29. Dadashi-Silab, S.; Doran, S.; Yagci, Y. Photoinduced Electron Transfer Reactions for Macromolecular Syntheses. Chem. Rev. 2016, 116, 10212-10275.

30. Peng, H.; Bi, S.; Ni, M.; Xie, X.; Liao, Y.; Zhou, X.; Xue, Z.; Zhu, J.; Wei, Y.; Bowman, C. N.; Mai, Y.-W. Monochromatic Visible Light "Photoinitibitor": Janus-Faced Initiation and Inhibition for Storage of Colored 3D Images. J. Am. Chem. Soc. 2014, 136, 8855-8858.

31. Wang, J.; Stanic, S.; Altun, A. A.; Schwentenwein, M.; Dietliker, K.; Jin, L.; Stampfl, J.; Baudis, S.; Liska, R.; Grutzmacher, H. A highly efficient waterborne photoinitiator for visible-light-induced three-dimensional printing of hydrogels. Chem. Commun. 2018, 54, 920-923.

32. Li, Z.; Zou, X.; Zhu, G.; Liu, X.; Liu, R. Coumarin-Based Oxime Esters: Photobleachable and Versatile Unimolecular Initiators for Acrylate and Thiol-Based Click Photopolymerization under Visible Light-Emitting Diode Light Irradiation. ACS Appl. Mater. Interfaces 2018.

33. Dadashi-Silab, S.; Aydogan, C.; Yagci, Y. Shining a light on an adaptable photoinitiator: advances in photopolymerizations initiated by thioxanthones. Polym. Chem. 2015, 6, 6595-6615.

34. Rosales, A. M.; Vega, S. L.; DelRio, F. W.; Burdick, J. A.; Anseth, K. S. Hydrogels with Reversible Mechanics to Probe Dynamic Cell Microenvironments. Angew. Chem. Int. Ed. 2017, 56, 12132-12136.

35. Tehfe, M.-A.; Dumur, F.; Vilà, N.; Graff, B.; Mayer, C. R.; Fouassier, J. P.; Gigmes, D.; Lalevée, J. A Multicolor Photoinitiator for Cationic Polymerization and Interpenetrated Polymer Network Synthesis: 2,7-Di-tert-butyldimethyldihydropyrene. Macromol. Rapid Commun. 2013, 34, 1104-1109.

36. Tehfe, M.; Dumur, F.; Graff, B.; Gigmes, D.; Fouassier, J. P.; Lalevée, J. Blue-to-Red Light Sensitive Push-Pull Structured Photoinitiators: Indanedione Derivatives for Radical and Cationic Photopolymerization Reactions. Macromolecules 2013, 46, 3332-3341.

37. Xiao, P.; Dumur, F.; Thirion, D.; Fagour, S.; Vacher, A.; Sallenave, X.; Morlet-Savary, F.; Graff, B.; Fouassier, J. P.; Gigmes, D.; Lalevée, J. Multicolor Photoinitiators for Radical and Cationic Polymerization: Mono vs. Polyfunctional Thiophene Derivatives. Macromolecules 2013, 46, 6786-6793. 38. Tar, H.; Esen, D. S.; Aydin, M.; Ley, C.; Arsu, N.; Allonas, X. Panchromatic Type II Photoinitiator for Free Radical Polymerization Based on Thioxanthone Derivative. Macromolecules 2013, 46, 3266-3272.

39. Zhao, J.; Lalevee, J.; Lu, H.; MacQueen, R.; Kable, S. H.; Schmidt, T. W.; Stenzel, M. H.; Xiao, P. A new role of curcumin: as a multicolor photoinitiator for polymer fabrication under household UV to red LED bulbs. Polym. Chem. 2015, 6, 5053-5061.

40. Cordon, C.; Miller, C., UV-LED: Presented by RadTech-The Association for UV \& EB Technology. RadTech International: 2013.

41. Pile, D. Ultraviolet goes solid-state. Nat. Photonics 2011, 5, 394-395.

42. Nakamura, S. The Roles of Structural Imperfections in InGaN-Based Blue Light-Emitting Diodes and Laser Diodes. Science 1998, 281, 956-961.

43. Ponce, F. A.; Bour, D. P. Nitride-based semiconductors for blue and green light-emitting devices. Nature 1997, 386, 351-359.

44. Dietlin, C.; Schweizer, S.; Xiao, P.; Zhang, J.; Morlet-Savary, F.; Graff, B.; Fouassier, J.-P.; Lalevee, J. Photopolymerization upon LEDs: new photoinitiating systems and strategies. Polym. Chem. 2015, 6, 3895-3912.

45. Zhang, J.; Frigoli, M.; Dumur, F.; Xiao, P.; Ronchi, L.; Graff, B.; Morlet-Savary, F.; Fouassier, J. P.; Gigmes, D.; Lalevée, J. Design of Novel Photoinitiators for Radical and Cationic Photopolymerizations under Near UV and Visible LEDs (385, 395 and 405 nm). Macromolecules 2014, 47, 2811-2819.

46. Zhang, J.; Lalevee, J.; Zhao, J.; Graff, B.; Stenzel, M. H.; Xiao, P. Dihydroxyanthraquinone derivatives: natural dyes as blue-light-sensitive versatile photoinitiators of photopolymerization. Polym. Chem. 2016, 7, 7316-7324. 
47. Zhang, J.; Hill, N. S.; Lalevée, J.; Fouassier, J.-P.; Zhao, J.; Graff, B.; Schmidt, T. W.; Kable, S. H.; Stenzel, M. H.; Coote, M. L.; Xiao, P. Multihydroxy-Anthraquinone Derivatives as Free Radical and Cationic Photoinitiators of Various Photopolymerizations under Green LED. Macromol. Rapid Commun. 2018, 1800172 (1-6).

48. Xiao, P.; Dumur, F.; Graff, B.; Fouassier, J. P.; Gigmes, D.; Lalevée, J. Cationic and Thiol-Ene Photopolymerization upon Red Lights Using Anthraquinone Derivatives as Photoinitiators. Macromolecules 2013, 46, 6744-6750.

49. Frisch, M.; Trucks, G.; Schlegel, H.; Scuseria, G.; Robb, M.; Cheeseman, J.; Scalmani, G.; Barone, V.; Petersson, G.; Nakatsuji, H.; Li, X.; Caricato, M.; Marenich, A.; Bloino, J.; Janesko, B.; Gomperts, R.; Mennucci, B.; Hratchian, H.; Ortiz, J.; Izmaylov, A.; Sonnenberg, J.; Williams-Young, D.; Ding, F.; Lipparini, F.; Egidi, F.; Goings, J.; Peng, B.; Petrone, A.; Henderson, T.; Ranasinghe, D.; Zakrzewski, V.; Gao, J.; Rega, N.; Zheng, G.; Liang, W.; Hada, M.; Ehara, M.; Toyota, K.; Fukuda, R.; Hasegawa, J.; Ishida, M.; Nakajima, T.; Honda, Y.; Kitao, O.; Nakai, H.; Vreven, T.; Throssell, K.; Jr, J. M.; Peralta, J.; Ogliaro, F.; Bearpark, M.; Heyd, J.; Brothers, E.; Kudin, K.; Staroverov, V.; Keith, T.; Kobayashi, R.; Normand, J.; Raghavachari, K.; Rendell, A.; Burant, J.; Iyengar, S.; Tomasi, J.; Cossi, M.; Millam, J.; Klene, M.; Adamo, C.; Cammi, R.; Ochterski, J.; Martin, R.; Morokuma, K.; Farkas, O.; Foresman, J.; Fox, D. Gaussian 16, revision A. 03. Gaussian Inc., Wallingford CT 2016.

50. Zhao, Y.; Truhlar, D. G. The M06 suite of density functionals for main group thermochemistry, thermochemical kinetics, noncovalent interactions, excited states, and transition elements: two new functionals and systematic testing of four M06-class functionals and 12 other functionals. Theor. Chem. Acc. 2008, 120, 215-241.

51. Weigend, F.; Ahlrichs, R. Balanced basis sets of split valence, triple zeta valence and quadruple zeta valence quality for H to Rn: Design and assessment of accuracy. Phys. Chem. Chem. Phys. 2005, 7, 3297-3305.

52. Marenich, A. V.; Cramer, C. J.; Truhlar, D. G. Universal Solvation Model Based on Solute Electron Density and on a Continuum Model of the Solvent Defined by the Bulk Dielectric Constant and Atomic Surface Tensions. J. Phys. Chem. B 2009, 113, 6378-6396.

53. Lalevée, J.; Blanchard, N.; Tehfe, M. A.; Peter, M.; Morlet-Savary, F.; Gigmes, D.; Fouassier, J. P. Efficient dual radical/cationic photoinitiator under visible light: a new concept. Polym. Chem. 2011, 2, 1986-1991.

54. Xiao, P.; Lalevée, J.; Allonas, X.; Fouassier, J. P.; Ley, C.; El Roz, M.; Shi, S. Q.; Nie, J. Photoinitiation Mechanism of Free Radical Photopolymerization in the Presence of Cyclic Acetals and Related Compounds. J. Polym. Sci., Part A: Polym. Chem. 2010, 48, 5758-5766.

55. Xiao, P.; Hong, W.; Li, Y.; Dumur, F.; Graff, B.; Fouassier, J. P.; Gigmes, D.; Lalevée, J. Green Light Sensitive Diketopyrrolopyrrole Derivatives used in Versatile Photoinitiating Systems for Photopolymerizations. Polym. Chem. 2014, 5, 2293-2300.

56. Borst, H. U.; Kelemen, J.; Fabian, J.; Nepraš, M.; Kramer, H. E. A. Triplet formation in aminoanthraquinones and its importance for the catalytic fading of dye mixtures. J. Photochem. Photobiol., A 1992, 69, 97-107.

57. $\quad$ Ritter, J.; Borst, H. U.; Lindner, T.; Hauser, M.; Brosig, S.; Bredereck, K.; Steiner, U. E.; Kühn, D.; Kelemen, J.; Kramer, H. E. A. Substituent effects on triplet yields in aminoanthraquinones: radiationless deactivation via intermolecular and intramolecular hydrogen bonding. J. Photochem. Photobiol., A 1988, 41, 227-244.

58. Allen, N. S.; Harwood, B.; McKellar, J. F. Lightfastness and spectroscopic properties of aminochloroanthraquinones. J. Photochem. 1978, 9, 559-564.

59. Tehfe, M. A.; Lalevée, J.; Telitel, S.; Contal, E.; Dumur, F.; Gigmes, D.; Bertin, D.; Nechab, M.; Graff, B.; Morlet-Savary, F.; Fouassier, J. P. Polyaromatic Structures as Organo-Photoinitiator Catalysts for Efficient Visible Light Induced Dual Radical/Cationic Photopolymerization and Interpenetrated Polymer Networks Synthesis. Macromolecules 2012, 45, 4454-4460. 
60. Lalevée, J.; Blanchard, N.; Tehfe, M. A.; Morlet-Savary, F.; Fouassier, J. P. Green Bulb Light Source Induced Epoxy Cationic Polymerization under Air Using Tris(2,2 '-bipyridine)ruthenium(II) and Silyl Radicals. Macromolecules 2010, 43, 10191-10195.

61. Lalevée, J.; Tehfe, M.-A.; Zein-Fakih, A.; Ball, B.; Telitel, S.; Morlet-Savary, F.; Graff, B.; Fouassier, J. P. N-Vinylcarbazole: An Additive for Free Radical Promoted Cationic Polymerization upon Visible Light. ACS Macro Lett. 2012, 1, 802-806. 


\section{For Table of Contents Use Only}

Disubstituted Aminoanthraquinone-based Multicolor Photoinitiators: Photoinitiation Mechanism and Ability of Cationic Polymerization under Blue, Green, Yellow and Red LEDs

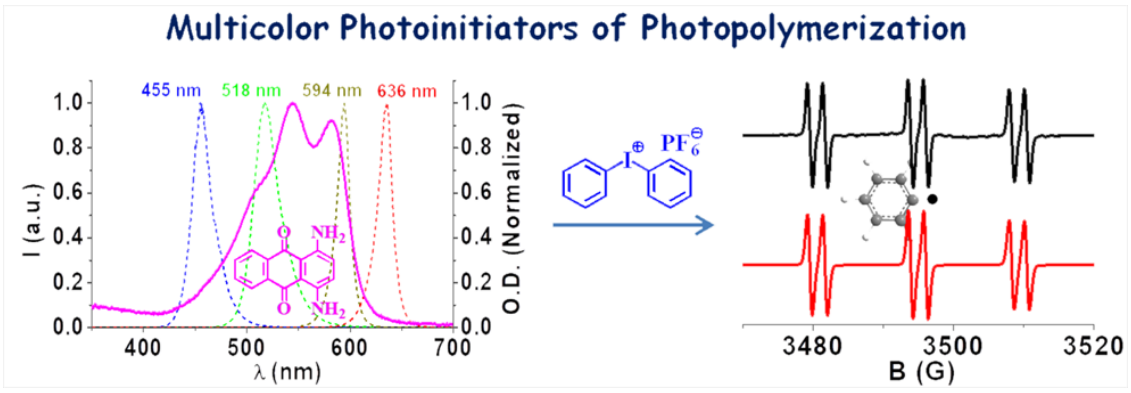

